\title{
Comprehensive Measurement Model for the Line Network Scale of Mod- ern Trams in New Urban Districts
}

\author{
Junhong $\mathrm{Hu}^{1,2}$, Haijun Zhang ${ }^{3}$, Xiucheng Guo ${ }^{1}$ \\ ${ }^{1}$ School of Transportation, Southeast University, Nanjing 210096, China \\ ${ }^{2}$ School of Transportation science \& Technology, Nanjing Tech University, Nanjing Jiangsu \\ 210009, China \\ ${ }^{3}$ Jiangsu Transportation Institute Nanjing Jiangsu 210017, China
}

KEYWORD: New urban district, modern tram, line network scale, measurement model

ABSTRACT: This paper presents the measurement index system of tram-line network on the basis of the defining of its scale of modern trams. The author makes a comprehensive measurement for the line network scale of modern trams in new urban districts by using measurement theory. Based on the uncertainty mathematic methods, the author sets up a comprehensive measurement model for the line network scale of modern trams in new urban districts, taking Hexi District in Nanjing as an analysis case. The results show that the comprehensive measurement model can accurately define the line network scale of modern trams in new urban district.

\section{Introduction}

Modern tram is a new rail mode among metros, light rails and conventional buses with medium traffic volume. Low-carbon transportation and green travel can be achieved with the development of modern trams in new urban district [1]. At present, there are a few researches on the comprehensive measurement of the line network scale of modern trams in new urban districts. What's worse, these researches generally focus on the simple analysis on part of indexes. This paper provides quantitative analysis on the total traffic volume, traffic structure, coverage of line network and level of service, etc. in new urban districts, and calculates the reasonable scale range for modern trams' line network in new urban districts and meanwhile sets up measurement model for the line network scale of modern trams in new urban districts, so as to make a reasonable definition on its scale. The author finally takes the line network planning of modern trams in Hexi District, Nanjing as an analysis case.

\section{The line network scale of modern trams in new urban districts}

A significant question in the measurement of the line network scale of modern trams is how to reasonably calculate its development scale [8]. The reasonable line network scale of modern trams can be defined from the traffic demands and the reasonable service coverage of line network.

\section{The definition of the line network scale of modern trams based on traffic demands}

The line network scale of the modern trams in new urban districts can be derived from the relationship between the total urban travel volume and the load intensity of modern trams' line network. The formula is as follows:

$$
L=q \alpha_{1} \alpha_{2} / \gamma_{1}
$$

Where $L$-length of line network, $\mathrm{km} ; q$ - total travel volume in new urban district, ten thousand passengers; $\alpha_{1}$ - proportion of public transportation, $\% ; \alpha_{2}$-proportion of modern tram in public transportation, $\% ; \gamma_{1}$-load intensity of modern trams' line network, ten thousand passengers/(km. day) .

In order to make quantitative analysis on the line network scale of modern trams, we define parameters in formula (1) as follows:

(1) The definition of total travel volume $q$. Due to the fact that the prospected life of line network measurement is far beyond that of comprehensive traffic measurement in urban, the line network scale of modern trams in new urban districts cannot be in accordance with the demanded traffic 
volume of prospected life. We, however, can derive it from the relationship between prospected population and traffic intensity:

$$
q=q_{1} \gamma_{2}
$$

Where: $\quad q_{1}$-prospected population (including resident and migrant population), ten thousand passengers; $\gamma_{2}$-traffic intensity time/(person. day).

(2) The definition of public transportation proportion $\alpha_{1}$. Compared with cities abroad, road square in our country is low while population density is high. Therefore, public transportation should be taken into priority, which means urban rail transportation should be developed as the backbone and conventional buses as main part. That is to say, the proportion of prospected public transportation should be more than $50 \%$. See Table 1 .

Table 1 the recommended proportion of public transportation among all travel modes.

\begin{tabular}{lcccl} 
Name & $\begin{array}{c}\text { Recent plan- } \\
\text { ning }\end{array}$ & $\begin{array}{c}\text { Medium-term } \\
\text { planning }\end{array}$ & Future planning & Remarks \\
\hline Small city & $45 \%$ & $50 \%$ & $60 \%$ & \\
Medium city & $55 \%$ & $55 \%$ & $65 \%$ & $\begin{array}{l}\text { proportion of public } \\
\text { transportation among } \\
\text { all travel modes }\end{array}$ \\
Big city & $60 \%$ & $65 \%$ & $70 \%$ & \\
Metropolitan & $65 \%$ & $70 \%$ & $80 \%$ &
\end{tabular}

(3) The definition of the proportion of modern trams in public transportation $\alpha_{2}$. The proportion of modern trams in public transportation is closely related to road network condition, density of conventional buses, service level of conventional buses, density of rail line network, transport speed, and distribution of stops. The proportion of modern trams in new urban districts in public transportation is shown in Table 2 .

Table 2 the recommended value for load intensity of line network (ten thousand passengers/(km. day)

\begin{tabular}{lcccl}
\hline \multicolumn{1}{c}{ Name } & $\begin{array}{c}\text { Recent } \\
\text { planning }\end{array}$ & $\begin{array}{c}\text { Medium- } \\
\text { term plan- } \\
\text { ning }\end{array}$ & $\begin{array}{c}\text { Future } \\
\text { planning }\end{array}$ & \multicolumn{1}{c}{ Remarks } \\
\hline Small city & $0.7 \sim 1.0$ & $1.0 \sim 1.5$ & $1.5 \sim 2.0$ & $\begin{array}{l}\text { Recommended val- } \\
\text { ue: } 0.7 \sim 1.2 \\
\text { Medium city }\end{array}$ \\
$\begin{array}{l}\text { Big city } \\
\text { Metropolitan }\end{array}$ & $1.0 \sim 1.5$ & $1.5 \sim 2.0$ & $1.7 \sim 2.5$ & $\begin{array}{l}\text { Recommended val- } \\
\text { ue: } 1.0 \sim 1.5\end{array}$ \\
\hline
\end{tabular}

\section{The definition of the line network scale of modern trams based on its service coverage}

As a part of the public transportation network, the modern trams should have a certain density of line network. In this paper, the line network scale of modern trams is derived from the relationship between the built-up square in new urban districts and the density of line network. See Formula 3.

$$
L=S \cdot \sigma
$$

Where: $L$-length of line network, $\mathrm{km} ; \mathrm{S}$ - built-up square in new urban districts, $\mathrm{km}^{2} ; \sigma$-density of line network, $\mathrm{km} / \mathrm{km}^{2}$. The parameters in Formula (3) are defined as follows:

(1) The definition of built-up square in new urban districts S. As the new urban districts usually lie at the edge of the city, it is a long traffic distance for residents. Hence, the attract range of modern trams' stop in suburban should be bigger than those in central urban.

In central city, most passengers who take rail transportation live within15-minute-on foot distance away from the stop with walking speed at $4 \mathrm{~km} / \mathrm{h}$. Generally speaking, they stay at the stop for 3-5 minutes. We thus can determine that the attract range of rail transportation in central city is 650 $800 \mathrm{~m}$ on both sides (appropriate at $750 \mathrm{~m}$ ). In new urban districts, the distance to the stop is 800 $1000 \mathrm{~m}$. In addition, the distance to transferring station by bike or by bus is less than 2 kilometers, from which we can determine that the attract range outside central city is $2 \mathrm{~km}$ on both sides ${ }^{[3]}$. 
Therefore, the attract range of a modern tram line in new urban district can be approximately determined within $2 \mathrm{~km}$ on both sides and attract range of a stop is $2 \mathrm{~km}$.

(2) The definition of the density of modern trams' line network in new urban districts $\sigma$. The main traffic flow in new urban districts is to the center of the city. So generally speaking, the modern tram line network only needs to meet the demands of passenger flowing to the central city. Thus the density of modern trams' line network can be approximately determined as $\sigma=0.25 \mathrm{~km} / \mathrm{km}^{2}$.

\section{The measurement index system of modern trams' line network}

The scale measurement of modern trams' line network is a great part in the measurement of line network in new urban districts. We set up a measurement index system for the line network scale of modern trams in new urban districts shown in Figure 1 according to the connotation and characteristics of modern trams as well as principles to set up the measurement index system for the line network scale of modern trams in new urban districts, and the research results on modern tram line network made by scholars at home and abroad, combined with the specific circumstances of each new urban districts.

The measurement indexes of the scale of modern trams in new urban districts not only have a typical significance but also can reflect the comprehensive characteristics of transportation system in new urban districts. Meanwhile, these indexes and their combinations can present quantitative judgment on the measurement of line network scale of modern trams. Each measurement index is independent, quantitative and universal.

\section{The measurement model for the line network scale of modern trams in new urban districts}

The modern tram in new urban districts is a complex system. We, therefore, use the fuzzy comprehensive measurement theory to classify many factors according to their characters. Firstly, we perform measurement according to factors in one category and then carry out comprehensive measurement among each category. The uncertainty mathematics method can be applied to define parameters in the whole process.

\section{Quantitative process of attribute value in measurement index}

Before making comprehensive definition to the line network scale of modern trams in new urban districts, standardization and normalization of attribute value in measurement index should be done in order to ensure its commensurability. The measurement indexes for the scale of modern trams' line network can be classified into two categories, one is quantitative measurement index and the other is qualitative measurement index, of which the standardization process methods are different. 


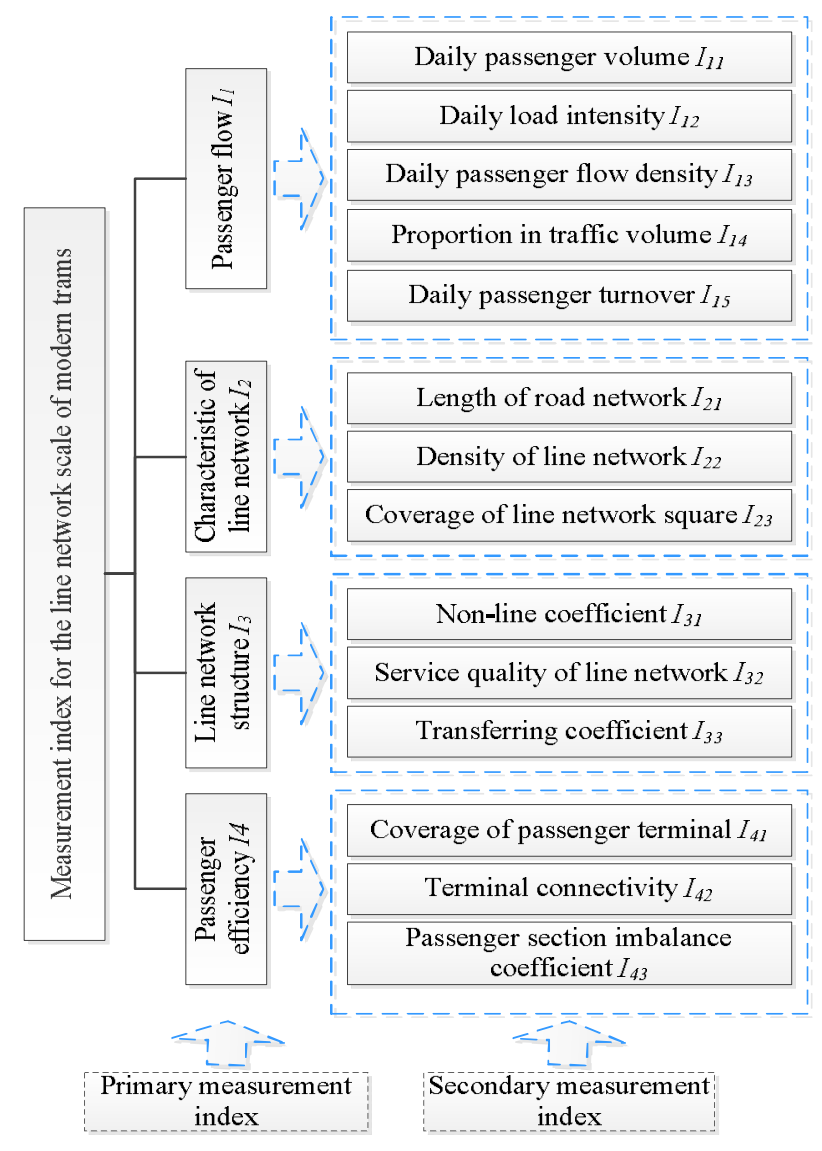

Figure 1measurement index for the scale of modern trams' line network

(1) Standardized process of quantitative measurement index

After the measurement index for the scale of modern trams' line network is confirmed, we can determine the attribute value $x_{\mathrm{ij}}$ of measurement index $I_{\mathrm{ij}}$ by looking up statistical data or by deriving calculation. The calculation methods of each measurement index value vary from each other due to different definitions of each measurement index for the scale of modern trams' line network in new urban districts. As a result, the dimensions of each measurement index are different from one another. We, therefore, have to perform standardization to measurement indexes to ensure its commensurability. Set

$J^{+}=\{$benefit measurement index $\}$

$J^{-}=\{$cost measurement index $\}$. Then

$r_{i j}=\left(x_{i j}-\min _{1 \leq i \leq n} x_{i j}\right) /\left(\max _{1 \leq i \leq n} x_{i j}-\min _{1 \leq i \leq n} x_{i j}\right),\left(i=1,2, \mathrm{~K}, n ; j \in J^{+}\right)$

$r_{i j}=\left(\max _{1 \leq i \leq n} x_{i j}-x_{i j}\right) /\left(\max _{1 \leq i \leq n} x_{i j}-\min _{1 \leq i \leq n} x_{i j}\right),\left(i=1,2, \mathrm{~K}, n ; j \in J^{-}\right)$

(2) Standardized process of qualitative measurement index

As for those indexes measured only by qualitative methods, there are many quantitative methods such as hierarchy analysis, Delphi method and so on. In this paper, the fuzzy mathematical language is applied to deal with the qualitative measurement index for scale of modern trams' line network, which changes to $[0,1]$, to ensure its commensurability. See Table 3

Table 3comment set on quantitative measurement index

\begin{tabular}{llllll}
\hline \multicolumn{1}{c}{ Comments } & Excellent & Good & Fair & Ordinary & Poor \\
\hline $\begin{array}{l}\text { Range of val- } \\
\text { ues }\end{array}$ & {$[0.9,1]$} & {$[0.8,0.9]$} & {$[0.7,0.8]$} & {$[0.6,0.7]$} & {$[0.5,0.6]$}
\end{tabular}

According to Table 4, we set the membership degree vector of qualitative measurement index for the scale of modern trams' line network $I_{i j}$ relative to the comments on measurement index $V=\{$ excellent, 
good, fair, ordinary, poor $\}$ as $v_{i}=\left(v_{i 1}, v_{i 2}, v_{i 3}, v_{i 4}, v_{i 5}\right)$, which is investigated by experts and determined by statistic methods of data collection.

\section{Construction of measurement model}

The construction of the comprehensive measurement model for the scale of scale of modern trams' line network in the new urban districts is as follows:

Step One - determine the object set, factor set, comment set, and weight set

(1) Object set: $\mathrm{O}=$ the line network scale of modern trams in new urban districts

(2) Factor set: is a measurement index set composed of many measurement indexes, mainly includes primary factor set and secondary factor set. The primary factor set of the line network scale of modern trams in new urban districts is

$I=\left\{I_{1}, I_{2}, I_{3}, I_{4}\right\}=$ passenger flow, scale of line network, structure of line network, passenger efficiency $\}$.

The secondary factors set of line network scale of modern trams in new urban districts is $I_{1}=\left\{I_{11}, I_{12}, I_{13}\right\}=$ daily passenger volume, daily load intensity, daily passenger flow density, proportion in traffic volume, daily passenger turnover $\}, I_{2}=\left\{I_{21}, I_{22}, I_{23}\right\}=\{$ length of road network, density of line network, coverage of line network square $\}, I_{3}=\left\{I_{31}, I_{32}, I_{33}\right\}=$ \{non-line coefficient, service quality of line network, transferring coefficient $\}, I_{4}=\left\{I_{41}, I_{42}, I_{43}\right\}=\{$ coverage of passenger terminal, terminal connectivity, passenger section imbalance coefficient $\}$.

Where: $I_{i j}$ represents the No. $j$ measurement index in the No. $i$ subset.

(3) Comment set: $V=\left(v_{1}, v_{2}, \mathrm{~L}, v_{5}\right)$ is a comment set, including excellent, good, fair, ordinary and poor. The comment set of line network scale for modern trams in new urban districts is defined by the above-mentioned five measurement grades.

(4) Weight set: $W=\left(w_{1}, w_{2}, \mathrm{~L}, w_{m}\right)$ is a weight coefficient set. If the weight coefficient of primary measurement index $I_{i} \quad(i=1,2,3,4)$ of line network scale for modern trams in new urban districts is $w_{i}$, the weight set is $W=\left(w_{1}, w_{2}, w_{3}, w_{4}\right)$. If the weight coefficient of secondary measurement index $I_{i j}(i=1,2,3,4 ; j=1,2, \mathrm{~L}, n)$ of line network scale for modern trams in new urban districts is $w_{i j}$, the weight set is $W_{i}=\left(w_{i 1}, w_{i 2}, \mathrm{~L}, w_{i n}\right)$.

Step Two - The fuzzy relationship from $\mathrm{X}$ to $\mathrm{V}$, set up fuzzy evaluation matrix.

The attribute value of measurement index can be calculated according to the type of measurement index and its quantitative method. Since many measurement indexes for the measurement of line network scale for modern trams in new urban districts can only be analyzed in qualitative way, we hence describe it in fuzzy measurement vector. According to Table 4, the fuzzy measurement vector of the measurement index $I_{i j}$ for the line network scale of modern trams in new urban districts is $v_{i j}=\left(v_{i j 1}, v_{i j 2}, v_{i j 3}, v_{i j 4}, v_{i j 5}\right)$.

Set

$$
r_{i j k}=v_{i j k} / \sum_{k=1}^{5} v_{i j k}
$$

then $r_{i j n}$ is the No. $i$ subset, the membership degree of the No. $j$ measurement index relative to the No. $\quad n$ grade of comments is $r_{i j n} \in[0,1]$.

Therefore, the measurement matrix of $I_{i i}$ is $R_{i j}=\left\{r_{i j 1}, r_{i j 2}, r_{i j 3}, r_{i j 4}, r_{i j 5}\right\}$ The fuzzy relationship from $\mathrm{X}$ to $\mathrm{V}$, we set up fuzzy evaluation matrix as follows:

$$
R_{i}=\left[\begin{array}{cccc}
r_{i 11} & r_{i 12} & \mathrm{~L} & r_{i 15} \\
\mathrm{M} & \mathrm{M} & \mathrm{M} & \mathrm{M} \\
r_{i n 1} & r_{i n 2} & \mathrm{~L} & r_{i n 5}
\end{array}\right]
$$

Step Three - Determine weight coefficient of measurement index

In order to avoid the subjective preference of the experts' empowerment, the objective evaluation method is adopted in this paper to determine the weight coefficient $I_{i j}$ of the measurement index of the modern trams' line network in new urban districts, which is

$$
w_{i j}=\left[\sum_{i=1}^{m} r_{i j}\right] \cdot\left[\sum_{i=1}^{m} \sum_{j=1}^{n} r_{i j}\right]^{-1}
$$


Therefore, the weight vector of the secondary measurement index for the scale of modern trams' line network is $W_{i}=\left(w_{i 1}, w_{i 2}, \mathrm{~L}, w_{i n}\right)$.

Step Four - Primary comprehensive measurement model is achieved by making use of synthetic relationship of fuzzy matrix

The primary measurement model for the line network scale of modern trams in new urban districts is achieved as follows based on the synthetic calculation of fuzzy evaluation matrix $R_{i}$ and weight vector of secondary measurement index $W_{i}=\left(w_{i 1}, w_{i 2}, \mathrm{~L}, w_{i n}\right)$.

$$
\begin{aligned}
B_{i} & =W_{i} \cdot R_{i} \\
& =\left(w_{i 1}, w_{i 2}, \mathrm{~L}, w_{i n}\right) \cdot\left[\begin{array}{cccc}
r_{i 11} & r_{i 12} & \mathrm{~L} & r_{i 15} \\
r_{i 21} & r_{i 22} & \mathrm{~L} & r_{i 25} \\
r_{i 31} & r_{i 32} & \mathrm{~L} & r_{i 35} \\
\mathrm{M} & \mathrm{M} & \mathrm{M} & \mathrm{M} \\
r_{i n 1} & r_{i n 2} & \mathrm{~L} & r_{i n 5}
\end{array}\right] \\
& =\left(b_{i 1}, b_{i 2}, \mathrm{~L}, b_{i n}\right)
\end{aligned}
$$

Step Five - Advanced comprehensive measurement model is achieved by making use of synthetic relationship of fuzzy matrix

Advanced comprehensive measurement index for the line network scale of modern trams in new urban districts is a further convergence of the attribute value of primary measurement index, the size of which reflects the scale trend of line network in the whole city. Based on the synthetic calculation between the fuzzy evaluation matrix $B_{i}$ and weight vector of primary measurement index $W=\left(w_{1}, w_{2}, w_{3}, w_{4}\right)$, we can achieve the advanced measurement model for the line network scale of modern trams in new urban districts.

$$
\begin{aligned}
B & =\left(w_{1}, w_{2}, w_{3}, w_{4}\right) \cdot\left(B_{1}, B_{2}, B_{3}, B_{4}\right)^{T} \\
& =\left(w_{1}, w_{2}, w_{3}, w_{4}\right) \cdot\left[\begin{array}{llll}
b_{11} & b_{12} & \mathrm{~L} & b_{15} \\
b_{21} & b_{22} & \mathrm{~L} & b_{25} \\
b_{31} & b_{32} & \mathrm{~L} & b_{35} \\
b_{41} & b_{42} & \mathrm{~L} & b_{45}
\end{array}\right]
\end{aligned}
$$

Step Six - Comprehensive measurement of the line network scale of modern trams in new urban districts

Set $F=\left(f_{1}, f_{2}, f_{3}, f_{4}, f_{5}\right)=(95,85,75,65,55)$ as a factional set. $f_{i}$ means the average value of the No. $i$ comment.

Then we calculate the final evaluation result of line network scale of modern trams in new urban districts using the vector product. Therefore the comprehensive measurement of line network scale of modern trams in new urban districts is as follows,

$$
Z=B \cdot F^{T}
$$

Step Seven - The grade standard of the comprehensive measurement of the line network scale of modern trams in new urban districts

We define the grade of comprehensive measurement $\quad Z$ of the line network scale for modern trams in new urban districts according to characteristics of measurement method we set up. The higher the $Z$ is, the better the line network scale for modern trams in new urban districts and vice versa. In order to make a quantitative analysis on the comprehensive measurement $Z$, we divide the measurement results of the line network scale of modern trams in new urban districts into five grades, as shown in Table 4 with reference to the comprehensive criteria of the development of modern trams in new urban districts and grading methods of comprehensive measurement in and abroad. 
Table 4Measurement range of the line network scale of modern trams

\begin{tabular}{cccccc}
\hline \begin{tabular}{c} 
Measurement $\begin{array}{c}\text { grade } \\
\text { grade }\end{array}$ \\
\cline { 2 - 6 }
\end{tabular} & $\begin{array}{c}\text { First } \\
\text { grade }\end{array}$ & $\begin{array}{c}\text { Second } \\
\text { grade }\end{array}$ & $\begin{array}{c}\text { Third } \\
\text { grade }\end{array}$ & $\begin{array}{c}\text { Fourth } \\
\text { grade }\end{array}$ & $\begin{array}{c}\text { Fifth } \\
\text { grade }\end{array}$ \\
\hline $\begin{array}{c}\text { Measurement } \\
\text { range }\end{array}$ & Good & Fair & Ordinary & Poor \\
\hline
\end{tabular}

The measurement range of $Z$ represents its corresponding grade referring to Table 5. For example, if $\mathrm{Z}=78$, that is $78 \in[70,80)$, its corresponding grade is the third grade, which means the line network scale of modern trams in new urban districts is fair.

\section{Case analysis}

Taking Hexi New District in Nanjing as an example, we, adopting the above-mentioned measurement index system of line network scale of modern trams in new urban districts, make a comprehensive measurement of the line network scale of modern trams that has been planned. Hexi New District lies in the southwest of Nanjing City, spanning longitudinally Jianye District, Gulou District and Xiaguan District. It starts at Sancha River in the north, connecting Qinhuai River in the south, facing Changjiang River in the west and extending to outer Qinhuai River and South River in the east. It is a new CBD integration of finance, business, trade, exhibition and sports. According to the planning of the line network scale of modern trams in Hexi New District, this paper elaborates the comprehensive measurement of line network scale of modern trams in this district using the measurement model for the line network scale of modern trams in new urban districts. The detailed process is as follows:

Step One - Determine the weight coefficient of measurement index

Calculate the weight coefficient index through the objective evaluation, from which we can obtain the weight coefficient of primary measurement index and secondary measurement index. See Table 5

Table 5The evaluation matrix and weight coefficient of modern tram line network scale

\begin{tabular}{|c|c|c|c|c|c|c|c|c|c|c|}
\hline \multicolumn{3}{|c|}{$\begin{array}{l}\text { Primary index and weight } \\
\text { coefficient }\end{array}$} & \multicolumn{3}{|c|}{ Secondary index and weight coefficient } & \multicolumn{5}{|c|}{$\begin{array}{c}\text { Fuzzy matrix and weight coeffi- } \\
\text { cient }\end{array}$} \\
\hline index & $\begin{array}{r}\text { weight } \\
\text { fici }\end{array}$ & $\begin{array}{l}\text { coef- } \\
\text { ent }\end{array}$ & index & weight & fficient & excellen & good & fair & ordinary & poor \\
\hline \multirow{5}{*}{$\begin{array}{l}\text { Passenger } \\
\text { flow }\end{array}$} & \multirow{5}{*}{$W_{l}$} & \multirow{5}{*}{0.28} & Daily passenger volume & $W_{11}$ & 0.22 & 0.4 & 0.4 & 0.1 & 0.1 & 0 \\
\hline & & & Daily load intensity & $W_{12}$ & 0.16 & 0.4 & 0.3 & 0.2 & 0 & 0.1 \\
\hline & & & $\begin{array}{l}\text { Density of daily passenger } \\
\text { flow }\end{array}$ & $W_{13}$ & 0 & 0.5 & 0.3 & 0.1 & 0 & 0.1 \\
\hline & & & $\begin{array}{l}\text { Proportion in traffic vo- } \\
\text { lume }\end{array}$ & $W_{14}$ & 0.20 & 0.6 & 0.2 & 0.1 & 0.1 & 0 \\
\hline & & & Daily passenger turnover & $W_{15}$ & 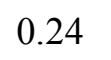 & 0.4 & 0.2 & 0.1 & 0.2 & 0.1 \\
\hline \multirow{4}{*}{$\begin{array}{l}\text { Characteristic } \\
\text { of line net- } \\
\text { work }\end{array}$} & \multirow{4}{*}{$W_{2}$} & \multirow{3}{*}{0.32} & Length of line network & $W_{21}$ & 0.35 & 0.4 & 0.3 & 0.2 & 0 & 0.1 \\
\hline & & & Density of line network & $W_{22}$ & 0.4 & 0.4 & 0.4 & 0.1 & 0.1 & 0 \\
\hline & & & Coverage of line network & $W_{23}$ & 0.25 & 0.4 & 0.3 & 0.2 & 0.1 & 0 \\
\hline & & & Non-line coefficient & $W_{31}$ & 0.3 & 0.4 & 0.3 & 0.2 & 0.1 & 0 \\
\hline \multirow[t]{2}{*}{$\begin{array}{l}\text { Structure of } \\
\text { line network }\end{array}$} & \multirow[t]{2}{*}{$W_{3}$} & \multirow[t]{2}{*}{0.22} & $\begin{array}{l}\text { Service quality of line } \\
\text { network }\end{array}$ & $W_{32}$ & 0. & 0.4 & 0.2 & 0.2 & 0.1 & 0.1 \\
\hline & & & Transferring coefficient & $W_{33}$ & 0.38 & 0.5 & 0.3 & 0.1 & 0.1 & 0 \\
\hline \multirow{3}{*}{$\begin{array}{l}\text { Passenger ef- } \\
\text { ficiency }\end{array}$} & \multirow{3}{*}{$W_{4}$} & \multirow{3}{*}{0.18} & $\begin{array}{l}\text { Coverage of passenger } \\
\text { terminal }\end{array}$ & $W_{41}$ & 0.35 & 0.6 & 0.2 & 0.1 & 0 & 0.1 \\
\hline & & & Terminal connectivity & $W_{42}$ & 0.33 & 0.6 & 0.2 & 0.1 & 0.1 & 0 \\
\hline & & & $\begin{array}{l}\text { Passenger section imbal- } \\
\text { ance coefficient }\end{array}$ & $W_{43}$ & 0.32 & 0.5 & 0.3 & 0.1 & 0.1 & 0 \\
\hline
\end{tabular}

Step Two - Determine the attribute value of primary measurement index for the line network scale of modern trams.

We can achieve the attribute value of primary measurement index for the line network scale of modern trams in Hexi New District according to the formulas of (6), (7), and (8) using the fuzzy matrix vector in Table 6. See Table 7. 
Table 6The fuzzy vector of primary measurement index

\begin{tabular}{cccccccc}
\hline $\begin{array}{c}\text { Primary measurement } \\
\text { index }\end{array}$ & & & & & \\
\cline { 1 - 5 } index & $\begin{array}{c}\text { weight coeffi- } \\
\text { cient }\end{array}$ & & & & & & \\
\multicolumn{7}{c}{ Calculation result of secondary fuzzy relation } & Measurement \\
\hline$I_{1}$ & $W_{l}=0.28$ & 0.458 & 0.278 & 0.116 & 0.090 & 0.058 & 75.98 \\
$I_{2}$ & $W_{2}=0.32$ & 0.400 & 0.340 & 0.160 & 0.065 & 0.035 & 74.3 \\
$I_{3}$ & $W_{3}=0.22$ & 0.438 & 0.268 & 0.162 & 0.100 & 0.032 & 77.35 \\
$I_{4}$ & $W_{4}=0.12$ & 0.568 & 0.232 & 0.100 & 0.065 & 0.035 & 74.27 \\
\hline
\end{tabular}

Step Three - Primary measurement of the line network scale for modern trams in Hexi New District Comprehensive measurement vector is calculated from formula (9): the single factor measurement result calculated from fuzzy relation in Table 7 is as follows:

$$
\begin{aligned}
& B_{1}=[0.458,0.278,0.116,0.090,0.058] \\
& B_{2}=[0.400,0.340,0.160,0.065,0.035] \\
& B_{3}=[0.438,0.268,0.162,0.100,0.032] \\
& B_{4}=[0.568,0.232,0.100,0.065,0.035]
\end{aligned}
$$

Step Four - Advanced measurement of the line network scale for modern trams in Hexi New District The advanced measurement vector of line network scale for modern trams in Hexi New District calculated from formula (10) is as follows:

$$
\begin{aligned}
B & =A \cdot R \\
& =[0.28,0.32,0.22,0.18] \cdot\left[\begin{array}{lllll}
0.458 & 0.278 & 0.116 & 0.090 & 0.058 \\
0.400 & 0.340 & 0.160 & 0.065 & 0.035 \\
0.438 & 0.268 & 0.162 & 0.100 & 0.032 \\
0.568 & 0.232 & 0.100 & 0.065 & 0.035
\end{array}\right] \\
& =[0.45484,0.28736,0.13732,0.07970,0.04078]
\end{aligned}
$$

Step Five - The comprehensive measurement of line network scale for modern trams in Hexi New District

The comprehensive measurement of line network scale for modern trams in Hexi New District calculated from formula (11) is as follows:

$$
\begin{aligned}
Z & =B \cdot F^{T} \\
& =[0.45484,0.28736,0.13732,0.07970,0.04078] \cdot[95,85,75,65,55]^{T} \\
& =85.3578
\end{aligned}
$$

Step Six - Define the line network scale grade of modern trams in Hexi New District

According to the measurement grade and standard range in Table 5, the comprehensive measurement $\mathrm{Z}$ of line network scale of modern trams in Hexi New District is $Z=85.3578$, that is $85.3578 \in[80,90)$. Its corresponding grade is the second, which means the line network scale of modern trams in Hexi New District is "good".

\section{Conclusion}

This paper mainly focuses on the analysis of factors affecting the line network scale of modern trams to set up measurement index system of line network scale and establish measurement model for the line network scale of modern trams in new urban districts. Finally the author takes Hexi New District in Nanjing as an example to make comprehensive measurement of the line network scale of modern trams in this district via the measurement model and the result shows that the measurement model 
that is set up can objectively, scientifically and reasonably define the line network scale of modern trams in new urban district, which provides significant basis for authorities' decision-making.

\section{References}

[1] Yao Zhisheng, Dong Chunjiao and Xiong Zhihua. Research on the forecasting method of transferring traffic flow in intercity rail transportation ([J]. Transportation System Engineering and Information, 2012, 13 (1): 119-123.

[2] Wu Qigang, Research on difficulties and solutions in the development of modern tram system [J]. Journal of Railways Engineering 2013, 30 (12): 89-92.

[3] Real J, Martínez P, Montalbán L, et al. Modelling vibrations caused by tram movement on slab track line[J]. Mathematical and Computer Modelling, 2011, 54(1): 280-291.

[4] Dunlop R L E, Caminer D M. Free TRAM breast reconstruction and ipsilateral interval pedicled TRAM reconstruction for second breast in one patient [J]. Journal of Plastic, Reconstructive \& Aesthetic Surgery, 2014.

[5] Li Yuankun and Miao Yanying, The inspiration for the development of modern tram abroad [J]. Transportation Research on Urban Rail, 2013, 16 (6): 29-33.

[6] Bai Yan, Wei Qingchao and Qiu Qingyun. Discussion on the development of urban traffic based on green transportation $[\mathrm{J}]$. Journal of Beijing Jiaotong University (social science edition) 2006, 32 (2): 10-14. 